\title{
Vegetarian Diets in Children-Some Thoughts on Restricted Diets and Allergy
}

\author{
Hermann Kalhoff ${ }^{1,2 *}$, Mathilde Kersting², Lennart Lücke², Thomas Lücke²,3 \\ ${ }^{1}$ Pediatric Clinic, Dortmund, Germany \\ ${ }^{2}$ Research Department of Child Nutrition (FKE), Pediatric University Clinic, Ruhr-University Bochum, Bochum, Germany \\ ${ }^{3}$ Pediatric University Clinic, Ruhr-University Bochum, Bochum, Germany \\ Email: ^hermann.kalhoff@klinikumdo.de
}

How to cite this paper: Kalhoff, H., Kersting, M., Lücke, L. and Lücke, T. (2021) Vegetarian Diets in Children-Some Thoughts on Restricted Diets and Allergy. International Journal of Clinical Medicine, 12, 4360.

https://doi.org/10.4236/ijcm.2021.122007

Received: November 30, 2020

Accepted: February 20, 2021

Published: February 23, 2021

Copyright (c) 2021 by author(s) and Scientific Research Publishing Inc. This work is licensed under the Creative Commons Attribution International License (CC BY 4.0).

http://creativecommons.org/licenses/by/4.0/

\begin{abstract}
Vegetarianism is a common diet worldwide. For a large proportion of people, meat or fish is not available at all or not regularly as a meal. But also in the industrialised countries, vegetarian nutrition is becoming more and more popular for various reasons. Many vegetarian parents also want a suitable diet for their children. But are restrictive diets beneficial or potentially harmful in certain situations, such as a predisposition to severe atopy? Are vegetarian diets equally suitable for pregnant women, nursing mothers, infants, children, and adolescents? What critical nutrients should parents, children, pediatricians, and nutritionists pay particular attention to? This article is focused on questions like these and discusses scientifically based concepts of nutrition. Main findings are that exposure to a variety of food antigens during early life may play a role in the development of healthy eating habits and that restrictive diets have not been found in studies to prevent allergic disease.
\end{abstract}

\section{Keywords}

Infants-Children-Adolescents, Nutrition, Vegetarian, Critical Nutrients, Dietary Supplementation, Food Allergy

\section{Trend towards Vegetarian Diet}

Vegetarian diets are common in poor countries where meat (and fish) are scarce and are only regularly available to a few families. For years, there has also been a trend towards vegetarian diets in wealthy countries. This trend is usually based on ethical, ecological and ideological attitudes; often, however, it is also justified in terms of health.

In the latest nutritional survey "EsKi-Mo" II, 2015-2017 in Germany, as part 
of the Child and adolescent health survey KiGGS, 3.4\% of children and adolescents were identified as vegetarians (1.5\% of 6 to 11 year olds; $5.1 \%$ of 12 - to 17-year-olds, [1]). According to the ProVeg Germany for adults the figures are around $10 \%$ for vegetarians and about $1 \%$ for vegans [2].

Many vegetarian parents want a corresponding diet for their children. From a pediatric-nutrionist's point of view, these diets need to be monitored very carefully. It is necessary to examine whether the respective diet can adequately and safely achieve all the high and specific nutrient needs of childhood and adolescence due to growth and development.

\section{Basic Dietary Concepts of the Research Department for Child Nutrition (FKE)}

In Germany, the Research Department for Child Nutrition (FKE) has developed scientifically based nutrition concepts for the entire growth-period. Starting with the "Dietary Scheme for the First Year of Life" [3], the concept of the "Optimized Mixed Diet" for children and adolescents (OMD) [4] [5] follows seamlessly. The OMD can also be the basis for the diet in pregnancy and lactation (Figure 1 and Figure 2).

Both concepts, the Dietary Scheme for the First Year of Life and the OMD are based on reference values for nutrient intake. Taking into account existing dietary habits, the nutrient references are translated into practical guidelines for family food choices [6] [7]. They also take into account aspects of the prevention of dietary related diseases such as obesity, cardiovascular diseases and diabetes. This is achieved, for example, by the quality of fat and carbohydrate intake and the preferred use of plant-based foods [6].

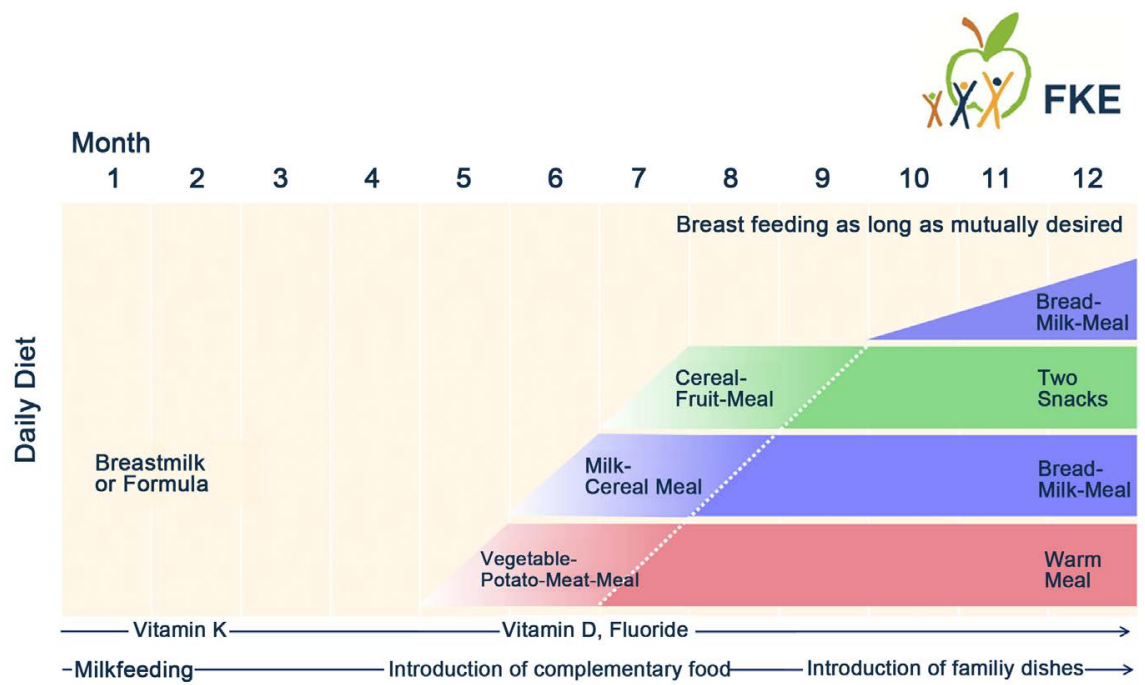

Figure 1. Dietary scheme for the first year of life. Department of Child Nutrition (FKE). Three main stages can be distinguished with smooth transitions between them: exclusive breastfeeding during the first months, introduction of complementary feeding along with partial breastfeeding during the second half of infancy, and introduction of family diet around the end of the first year of life. 


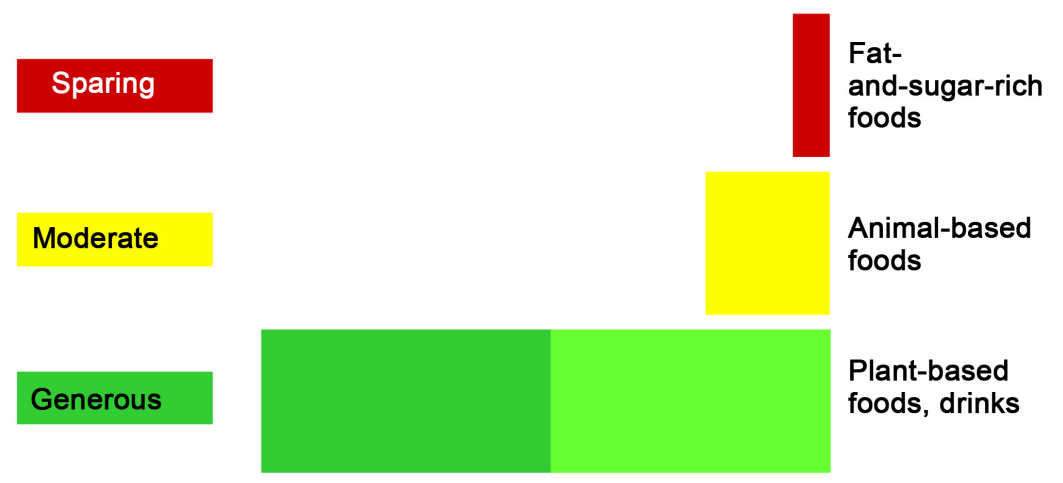

Figure 2. "Optimized Mixed Diet" for children and adolescents. Important dietary recommendations can be summarized in three simple rules. Department of Child Nutrition (FKE).

The European Food Safety Authority (EFSA) has identified these modular foodbased approaches with calculated nutrient intake as exemplary for child nutrition in Europe [8]. The "Dietary Scheme for the First Year of Life" and the "Optimized Mixed Diet” are scientific reference instruments for child nutrition in Germany [9] [10]. Due to the practical and realistic suggestions, they are the basis for nutrition counselling by pediatricians and nutritionists in the field of child nutrition [6].

\subsection{Diet in the First Year of Life}

In infant nutrition, a meal based on vegetables and potato is introduced for the start of complementary feeding between the 5th to 7th month of life. It is important that iron with high bioavailability is supplied by meat as a further ingredient, since the iron reserves of infants are exhausted at this age (Table 1).

\subsection{Standard for Children and Adolescents: Balanced Mixed Diet}

In the diet of children and adolescents, plant-based foods are the basis. Therefore they should be consumed abundantly. Animal-based products are recommended in moderate amounts as carriers of specific nutrients. These are, for example, calcium and iodine in milk (products), iron and zinc in meat, iodine and long-chain, polyunsaturated omega- 3 fatty acids in sea fish. The concept of the "Optimized Mixed Diet" combines the preventive potential of a plant-focused diet with the security of a sufficient nutrient supply (Figure 2).

The calculated and proven concepts for the nutrition of infants, children and adolescents in Germany guarantee an adequate supply of nutrients with a high degree of certainty. This applies to all pediatric age groups.

\section{Early Diet in Infants and Children and Development of Food-Allergy}

Food allergy affects an estimated $8 \%$ of the global population, with evidence of increasing prevalence among children in developed countries [11]. Thus, there is 
Table 1. Study situation on vegetarian diet in children [53] [54].

\begin{tabular}{ccccc}
\hline Country & Year of study & $\begin{array}{c}\text { No. of study } \\
\text { groups }\end{array}$ & $\begin{array}{c}\text { Number of study } \\
\text { participants }\end{array}$ & $\begin{array}{c}\text { Age of children } \\
\text { (years) }\end{array}$ \\
\hline Great Britain & $1980-1990$ & 3 & $20-50$ & $0-11$ \\
Netherlands & $1980-1990$ & 1 & $50-209$ & $0-17$ \\
Germany & $1991^{1}$ & 1 & 13 & $0-1$ \\
USA & $1991^{1}$ & 3 & $39-404$ & $0-12$ \\
Slovakia & $1997^{1}$ & 1 & $26-32$ & $11-15$ \\
Belgium & $1999^{1}$ & 1 & 38 & $6-17$ \\
Poland & $2003-2011$ & 5 & $2-50$ & $2-18$ \\
\hline
\end{tabular}

${ }^{1}$ Not clearly deducible from the publication.

great interest in any nutritional strategies that may ameliorate or prevent the development of food allergies, especially in atopic infants. Around the turn of the century, international guidelines pushed for delayed introduction of complementary allergenic foods to slow the rise [12]. However, food allergy incidence continued to increase in developed countries [13].

While the exact etiology of food allergies is still unknown, research suggests a complex interaction between the immune system, rising susceptibility due to environmental factors, feeding habits, and genetics. Diet plays a crucial role in both the prevention and management of food allergies. A number of factors, including the maternal diet, the microbiome and early life feeding, have been investigated for the prevention of allergic diseases. As a consequence of currently available data, the traditional avoidance diet during infancy has been, in recent years, completely reconsidered.

As an example, the EAT-trial demonstrated, there is no evidence, that delaying the introduction of foods with high allergenic potential (e.g. peanut, eggs, fish) beyond 4 - 6 months prevents development of atopic disease [14]. Moreover, in the LEAP trial, early introduction of peanuts products was even associated with a significantly lower prevalence of peanut allergy in severely atopic infants [15]. A follow-up study demonstrated that this effect of early peanut consumption was long-lasting, thus comparable to induction of tolerance [16].

\section{Allergy Prevention}

In respect of allergy prevention, the following nutritional aspects should be considered:

\subsection{Breastfeeding}

Studies have shown that perinatal administration of probiotics to mothers during the last weeks of pregnancy and to infants in the first few months of life was associated with a significant reduction in atopic eczema [20].

As widely known, breastfeeding has many benefits for the mother and child 
[17]. However recent studies show few evidence for breastfeeding generally being protective against food allergies and allergic disorders [18]. Boyle et al. have published a review in 2016 assessing the impact of hydrolysate formulas on the risk for allergy and autoimmune diseases. Results do not recommend the use of such formulas to prevent allergic diseases in high risk infants [19]. In the following, countries such as Switzerland withdrew recommendations for hydrolysate formulas.

\subsection{Probiotics}

Studies have shown that perinatal administration of probiotics to mothers during the last weeks of pregnancy and to infants in the first few months of life was associated with a significant reduction in atopic eczema [20].

\subsection{Perinatal Diets and Allergen Induction}

Studies have shown that maternal diet before and during the pregnancy influences the risk of allergy and asthma in children [21]. Higher maternal intake of possible allergens such as peanut, milk, and wheat during early pregnancy are associated with reduced odds of mid-childhood allergy and asthma [22]. Early on exposure to known allergens has been assessed in large prospective studies. Despite difficulties with the compliance of test groups, results show protective effects of early allergen induction in patients with both high and normal risk. These conclusions were published by various studies where high- and normal risk children ingested allergen-mixes [23] and single allergens such as fish [24], peanuts [25], eggs [26] and cow's milk [27].

In already established allergic disorders, therapeutic effects can be achieved by desensitization through allergen-exposure. Patients with confirmed food-allergies are frequently treated with personalized long-term immunotherapies [28]. However oral or subcutaneous injections of allergens often do not lead to long termdesensitization.

\subsection{Omega 6/3 Fatty Acid Supply}

An association between food allergies and decreased Vitamin D levels has been shown in several studies. Especially during the first year of life, Vitamin D appears to have a crucial role in the modulation of the immune system. This postulation has been supported by the LINA Study. Low maternal and infant Vitamin D blood levels were associated with increased risk for food allergies [32].

According to various studies, the ratio between Omega 6 and Omega 3 fatty acids seems to have an impact on the development of allergies. The strongest associations were found in children $<4$ years [29]. High maternal Omega 6 fatty acid blood levels may lead to increased risk for allergic outcomes, especially eczema [24]. Omega 6 fatty acid consumption should be kept to moderate levels in high risk individuals. Increased Omega 6 fatty acid levels are predominantly due to vegetable oil consumption. As such, e.g. butter when compared with margarine (plant-based fatty acids) consumption evidently reduces the risk for aller- 
gic diseases [30]. Fish, as rich source in Omega 3-FA can improve the Omega 6: Omega 3 FA-Ratio and as such evidently reduces risk for atopy [24].

A high Omega 6: Omega 3 fatty acid ratio however may not only be due to dietary factors. Genetic defects have shown to be additive to deregulation, according to the KOALA and LISA Studies [31].

\subsection{Vitamin D}

An association between food allergies and decreased Vitamin D levels has been shown in several studies. Especially during the first year of life, Vitamin D appears to have a crucial role in the modulation of the immune system. This postulation has been supported by the LINA Study. Low maternal and infant Vitamin D blood levels were associated with increased risk for food allergies [32].

\subsection{Fruits and Vegetables}

Studies have shown a significantly lower risk to develop asthma in individuals with high fruit and vegetable consumption, when compared to individuals with low fruit and vegetable consumption. Same results were found in children of mothers with high fruit consumption during pregnancy. Also, high fruit consuming patients with already diagnosed asthma presented with significantly higher FEV1 and less severe exacerbations than when compared with individuals consuming few fruits. [33] Detailed discussion on dietary asthma prevention would surpass the aim of this article. Further information can be found in the referenced review-article [34]. For recent recommendations regarding prevention of food-allergy and atopic diseases we refer to reviews [35] [36].

\section{Examples for Indicated Restrictive Diets in Patients with Allergic Diseases}

\subsection{Empiric Elimination Diets}

Empiric Elimination diets (such as Six-Food-Elimination-Diet; SFED) are used extensively in cases of confirmed, specific allergic reactions. When used in treatment of Eosinophilic Esophagitis, SFED correlates with histologic recession in $74 \%$ of children [37].

\subsection{Specific Restrictive Diets}

Efficiency of specific restrictive diets, even as first line treatment for food allergies and allergic diseases, is well documented. In some diseases, specific exclusion diets are indicated. Examples of such diseases are: Food Protein-Induced Enterocolitis Syndrome (FPIES), Histamine Intolerance, WDEIA (Wheat dependent Exercise Induced Anaphylaxis), Regular Food-Allergy and metabolic diseases such as Phenylketonuria (PKU).

In already established allergies, or atopic diseases, specific restrictive diets frequently are the gold standard for treatment. Restrictive diets may be suspected to have a preventive effect on food allergies in children. PKU-patients, treated 
with phenylalanine-low-diet, were discussed to be at lower risk for allergic sensitization in certain age groups, when compared with healthy individuals on an omnivore diet [38]. For the several other medically indicated, specific restriction diets, no data was found regarding impact on allergy or atopy related diseases. Further investigations should be conducted to assess the impact of restrictive diets on allergy.

\section{Possible Benefits of a Vegetarian Diet}

In nutritional epidemiology, the relationship between plant-based and animalbased foods, as well as the degree of processing of food, is considered a factor influencing the preventive impact of the diet on so-called diseases of civilization. For example, epidemiological studies have shown that high consumption of meat products can increase the risk of single-celled cancers [39]. Furthermore, high proportions of fiber-rich cereal products as well as vegetables and fruit can reduce individual risks of illness, e.g. in cardiovascular diseases [40] or in diabetes mellitus type 2 [41]. Vegetarian diets are often more favorable from these preventive medical points of view than the usual diet in many Western countries [42].

Recent studies propose microbiome-related pathways, by which plant-based diets might modulate the gut microbiome towards a favorable diversity of bacterial species. However, little is known about speculative cognitive effects linked to plant-based diets. Thus, a causal impact of plant-based diets on cognitive functions, mental and neurological health has yet to be demonstrated [43].

\subsection{Meta-Analyzes on Vegetarian Diets}

A recent meta-analysis of various observational studies found that people on a vegetarian diet had a lower risk of cardiovascular disease and cancer compared to people without a vegetarian diet [44]. Furthermore, in children, a preventive effect on obesity is discussed under vegetarian diets [45]. According to a meta-analysis, vegetarian based diets are associated with lower levels of inflammatory mediators such as C-reactive protein, fibrinogen and total leukocyte counts when compared with omnivore individuals [46]. No data however has stated a decreased incidence of allergic disease in individuals on vegetarian diets. No evidence was found to support maternal restrictive diets during pregnancy or lactation [35]. Possible Effects of such restrictive diets require further assessment. Sufficient nutritional supplies should be assessed and monitored.

At second glance, there are some critical points in these studies. Groups of people with vegetarian diets systematically differ from the average population in typical health-related risk factors. For example, they differ in a younger age or a lower body mass index. In addition, the lifestyle of vegetarians is often healthy, e.g. with less alcohol, less smoking and more physical activity. The following criteria apply to typical vegetarians in western countries: mostly female, young, educated and affluent, city dweller, healthy lifestyle [47]. 


\subsection{Analysis of Two Prospective Studies}

The difficulty of definitively proving separate health-promoting properties of vegetarian diets beyond lifestyle factors is demonstrated, among other things, by the analysis of two prospective studies. These compared mortality between people with vegetarian diets and those with a mixed diet which was also plant-focused and containing small amounts of meat and butcher's products. The analysis found no difference between these two groups [48]. Several other reviews are in line [42] [49] [50].

\section{Risks of Vegetarian Diets for Children}

If a diet differs from the established and safe standards for feeding children, it must be demonstrated-before it can be considered a population-based recommendation-that the diet ensures growth and developmental needs and covers the specific nutritional needs for all age groups. However, if entire groups of food are excluded, as in vegetarian diets, there is a considerable risk that individual nutrients required for the nutrition of children and adolescents are only supplied in critically low or even inadequate amounts [51]. The more restrictive the diet and the younger the children, the greater the risk of inadequate intake of critical nutrients.

Theoretically, critically reduced nutrients can be identified for individual restrictive diets in childhood [52]. Similarly, a supplementary intake of critical nutrients can theoretically compensate for an inadequate supply induced by food exclusion. However, the practical application of this principle is impaired by the fact that the mere indication of a vegetarian diet by the parents does not allow certain conclusions to be drawn about the individual nutrition practices. In addition, the current study situation on vegetarian diets in children in Europe and the USA is unsatisfactory, with only a few studies carried out in the 1980s and most of them in the 1980s-1990s (Table 1). These studies do not allow to draw valid conclusions about current dietary practice and health status in vegetarian-fed children in Germany [53] [54]. New results may be expected from the ongoing VeChi-Diet study.

Little information is available on the effects of a vegetarian diet on the risk of allergies. In one study, it was even observed that vegetarians were more affected by allergies than subjects with other eating habits [55].

Aside from individuals on "voluntary" restrictive diets, attention should also be raised at patients with established allergic diseases. Patients are often managed with exclusion of offending food(s). Especially in children, this could lead to nutrient insufficiencies due to wide range-exclusion. Upon adulthood, patients were found to be more susceptible for possibly harmful extreme-nutrition regimes [56].

\section{Categories of Vegetarian Diets}

The collective term vegetarian diet includes different sub forms. According to the exclusion of food groups, the following forms of vegetarianism can be dis- 
tinguished:

Lacto-Ovo vegetarians: abstain from the consumption of meat and fish (killed animals) but accept eggs and milk.

Lacto vegetarians: abstain from the consumption of meat, fish, eggs, but use milk.

Vegans: eat exclusively plant-based foods. In addition to fish and meat, they also abstain from milk, dairy products, and honey.

As a separate group, so called "semi-vegetarians or flexitarians" eat occasionally meat or fish, similar to seven-day Adventists which are, however, often classified as "vegetarians" (Table 2). However, in real life there are mostly barely recognizable transitions between different vegetarian forms of food. A general rule for assessing possible risks is: the more restricted the child's diet, the greater the risk of deficiency, and this is by far the highest in vegan children.

\subsection{Lacto-Ovo-Vegetarian Food}

This form of diet is most practiced among vegetarians. Compared to a standard diet under mixed food, animal protein and further nutrients such as iron, zinc, vitamin B12 (in meat) as well as iodine and long-chain, polyunsaturated omega-3 fatty acids (in fish) are reduced in this diet. When summarized, there is no increased risk of growth and development for children and adolescents [58] [59].

However, for individual groups of subjects who already have an increased risk of nutrient deficiency, such as iron, with the recommended mixed diet, the situation must be considered more carefully. This applies, for example, to female adolescents and infants in the second 6 months of their lives [60].

Moreover, children with allergy may have increased nutritional needs due to comorbidity. Limited consumption of important nutrients, lack of dietary variety and/or reduced bioavailability may enhance the risk for complications. As such, the coexistence of allergy or allergic diseases and restrictive diets may increase risk for malnutrition [61].

Table 2. Vegetarian diets and reduced nutrients in children [57].

\begin{tabular}{|c|c|c|}
\hline Diet & Excluded foods & Reduced nutrients \\
\hline Lacto-ovo-vegetarian & Meat, fish & $\begin{array}{l}\text { Meat: animal protein, Fe, Zn (high } \\
\text { bioavailability), Vit. B }{ }_{12} \text {; Fish: Iodine, } \\
\text { n-3-LC-PUFA, Vit. D }\end{array}$ \\
\hline Lacto-vegetarian & Meat, fish, and eggs & $\begin{array}{l}\text { as above. } \\
\text { additionally: animal protein, Vit. D, A }\end{array}$ \\
\hline Vegan & $\begin{array}{l}\text { Meat, fish, eggs, and } \\
\text { milk }\end{array}$ & $\begin{array}{l}\text { as above. } \\
\text { additionally: animal protein, } \mathrm{Vit} . \mathrm{B}_{12}, \mathrm{Ca} \text {, } \\
\text { Iodine, Vit. } \mathrm{B}_{2}, \mathrm{~A}\end{array}$ \\
\hline
\end{tabular}

Fe: Iron, Zn: Zinc, Vit.: Vitamin, n-3-LC-PUFA: long-chain, polyunsaturated omega-3 fatty acids, Ca: calcium, LM: food. 


\subsubsection{Iron Status in Infants}

The increasing risk of iron deficiency in infants with low iron intake is well documented by European data [62]. New data show that the iron status in infants in Germany has worsened in recent years, despite counseling on nutrition based on the "Dietary Scheme for the First Year of Life". Reasons include the decrease in the iron content in formula foods and in the meat content in jar foods. About $30 \%$ of the infants had a lack of storage iron at the age of 10 months, but did not show anemia nor clinical signs [63] [64].

Under a lacto-ovo-vegetarian diet, the absence of meat excludes the particularly bioavailable form of $\mathrm{Fe}^{2+}$ (approx. 20\%) from the diet. As a compromiselike replacement, whole grains with (poorly absorbable) trivalent iron (approx. $3 \%$ ) can be used instead of meat. The recommended combination of $\mathrm{Fe}^{3+}$ with vitamin C-rich ingredients improves absorption (Table 3). In Germany, however, no data is available on the actual implementation of these recommendations and on iron status in infants on vegetarian diets.

\subsubsection{Other Potentially "Critical" Nutrients during Growth}

There is insufficient data and surveys for the following nutrients [54] [65]: vitamin B12, zinc, iodine, long-chain polyunsaturated omega-3 fatty acids; all of these have a potentially reduced intake under a lacto-ovo-vegetarian diet.

In conclusion: already with lacto-ovo-vegetarian diets, the safe supply of critical nutrients by individual nutritional history should be clarified in situations with an increased risk for critically low intake. In individual cases, it is necessary to obtain additional laboratory data.

\subsection{Vegan Diet}

A vegan diet threatens multiple nutrient deficits and a lack of energy. In addition to the restrictions under the lacto-ovo-vegetarian diet, calcium, iodine, vitamin B2 and vitamin D (milk) are reduced. Vitamin B12 and animal protein with a

Table 3. Standard recipe for a home-made meat-containing meal according to the "Dietary scheme for the first year of life and conversion to a vegetarian meal." Department of child nutrition (FKE).

\begin{tabular}{ccc}
\hline & \multicolumn{1}{c}{ Standard recipe } & Vegetarian recipe \\
\cline { 2 - 3 } Ingredients & Vegetable potato meat meal & Vegetable potato and cereal meal \\
\cline { 2 - 3 } & Amount (g) & \\
\hline Vegetable & $90-100$ & $90-100$ \\
Potatoes & $50-60$ & $50-60$ \\
Meat & $20-30$ & 10 \\
Cereals (whole grain) & - & 20 \\
Water & $15-20$ & 30 \\
Fruit juice, fruit-puree & $8-10$ & $8-10$ \\
Rapeseed oil & & \\
\hline
\end{tabular}


high biological value (measured by the amino acid pattern) are missing [54] [66].

The diet induced deficits compared to the age-corresponding nutrient requirements either cannot be compensated or can only be partially compensated by the foods permitted in the vegan diet. However, a complete balance of foodinduced deficits is essential but requires specific knowledge of the composition of food and the use of nutrient-enriched foods and supplements. With the heterogeneous market supply of foods and preparations, proper advice is extremely difficult even for qualified nutritionists and doctors. Accordingly, studies in Germany showed trends of undersupply of protein and many micronutrients in adult vegans [67]. In children in Eastern Europe under a vegan diet, studies showed lower levels of vitamin $\mathrm{D}$ and reduced bone mass compared to children on a mixed diet [68].

\subsubsection{Vitamin B12}

Numerous case reports, some of which are from Germany, reported deficiency of vitamin B12 in breastfed infants of vegan mothers with anemia and additionally, partly irreversible, neurological disorders [69] [70]. Under a vegan diet, however, not only infants, but also children and young people of all age groups must be supplemented with vitamin B12 [71]. A particular medical problem is the insufficient supply of vitamin B12 to breastfed babies of vegan mothers.

\subsubsection{Indication for Industrially Produced Food}

In infant nutrition, industrially produced soy formula for infants is an animalprotein-free diet and must comply with the legislation of the European Union (EU) for infant formulae and follow-on formulae. A soy-formula can be a valuable source of protein and is enriched with other nutrients. In term infants there are only few indications for use of a soy-formula in place of cow milk-based formula. These indications include infants with galactosemia and hereditary lactase deficiency (both of which are rare) and in situations in which a vegetarian diet is preferred. For infants with cow milk protein allergy, extensively hydrolyzed protein formula should be considered as first choice, as $10 \%$ to $14 \%$ of these infants will also have a soy protein allergy [72].

With a vegan diet, soy-formula can also be used beyond infancy. However, the safety of milk substitute products for children is under discussion. Concerns are based on in vivo and in vitro data that raise the possibility of estrogenic effects of isoflavones contained in soy-formula [73].

\subsection{Dietary Strategies on a Vegan Diet}

A vegan diet increases the risk of an inadequate supply of multiple nutrients in children. This goes hand in hand with an increased risk of developing damage or developmental disorders.

Therefore, elaborate dietary strategies and continuous elaborate substitution must be ensured persistently. The effort to cover the nutritional deficits under 
vegan diets is quite comparable with the effort to avoid deficiency symptoms in subjects on medically necessary diets with complex dietary gaps (e.g., complex food allergies, congenital metabolic diseases). As an example, in all patients with phenylketonuria, nutritional, clinical, and biochemical follow-up is necessary, regardless of therapy [74]. Dietary records provide indications of possible critical nutrients and the need for possible further diagnostics and individual dietary counseling. In children on a vegan diet, the course of growth and development is to be recorded regularly. Families on vegan diets need advice and support in which pediatricians and nutritionists cooperate. Good compliance is imperative [75].

\section{Opinions on Vegetarian Diets in Children}

The positions of renowned institutions on vegetarian nutrition in children are accented differently; probably also as a result of the insufficient study situation [54].

\subsection{American Dietetic Association and American Academy of Pediatrics}

The American Dietetic Association, like the American Academy of Pediatrics, considers vegetarian diets, including vegan diets, to be suitable for all phases of life only if, for the entire duration of the vegetarian diet, the otherwise inadequate supply is balanced with a high number of nutritional measures [52] [74].

\subsection{German Society for Nutrition}

The German Society for nutrition (DGE) considers that special care is necessary for pregnant women, breastfeeding women, infants, and toddlers on lacto-ovovegetarian nutrition. A purely plant-based, vegan diet is not recommended during pregnancy and lactation as well as during the entire childhood and adolescence [50].

\subsection{ESPGHAN}

The European Society for Pediatric Gastroenterology, Hepatology and Nutrition (ESPGHAN) emphasizes the special risks of a vegan diet for children (insufficient intake of vitamin B12, D, folic acid, iron, Zinc, calcium, n-3 fatty acids, protein) [12].

\section{Conclusions}

Taken together, the current evidence indicates that maternal avoidance of allergenic solids during pregnancy or breastfeeding and the delayed introduction of such foods in infants' diets after the first year of life are ineffective means of food-allergy prevention. They are no longer recommended by international guidelines. Similarly, there is no evidence that very early exposure, before four months of age, to foods with high allergenicity can prevent food allergies both in stan- 
dard risk and high-risk infants. Although recent data suggest considering early introduction of allergenic solids as a potential strategy to tackle the rise in foodallergy prevalence, convincing evidence for such practice is currently available only for peanuts in high-risk infants between 4 and 11 months of life, but not for most other allergenic foods [76] [77]. So far, the recommendations on exclusive breastfeeding over 4 - 6 months, avoiding environmental tobacco smoke and avoidance of overweightness remain unchanged.

In the discussion between supporters of vegetarian diets and pediatricians and nutritionists, ideological arguments and mutual reproaches are not effective. Rather, high-quality studies are needed to evaluate the supply of infants, children, and adolescents with nutrients. These studies should address, on an evidence-based basis, health risks and dietary prevention options for various forms of vegetarian diets, but for standard nutrition concepts as well. New findings on the probably protective effect of an increased diversity of food introduced in the first year of life on allergic diseases are consistent with the hypothesis that exposure to a variety of food antigens during early life might play a role in the development of healthy eating habits. Restrictive diets were not found to be preventive for allergic diseases. Further research is required to understand immunological-allergic trigger pathways and to be able to construct food-recommendations with minimal risk for allergy development in children.

\section{Author Contributions}

Conceptualization, HK, MK.; original draft preparation, HK; review and editing, LL; reviewing and supervision, TL; All authors have read and agreed to the published version of the manuscript.

\section{Conflicts of Interest}

The authors declare no conflict of interest.

\section{References}

[1] Patelakis, E., Lage-Barbosa, C., Haftenberger, M., et al. (2019) Prevalence of Vegetarian Diet among Children and Adolescents in Germany. Results from EsKiMo II. Ernährungs Umschau, 66, 85-91.

[2] Vegetarierbund (2019). https://proveg.com/de/ernaehrung/anzahl-vegan-vegetarischer-menschen/

[3] Kersting, M., Alexy, U. and Clausen, K. (2005) Using the Concept of Food Based Dietary Guidelines to Develop an Optimized Mixed Diet (OMD) for German Children and Adolescents. Journal of Pediatric Gastroenterology and Nutrition, 40, 301 308. https://doi.org/10.1097/01.MPG.0000153887.19429.70

[4] Kersting, M., Kalhoff, H. and Lücke, T. (in preparation) Translation of European Nutrient References into Practice-The Optimized Mixed Diet (OMD) for Children and Adolescents in Germany.

[5] Kersting, M., Kalhoff, H., Voss, S., Jansen, K. and Lücke, T. (2020) Translation of EU Food Law and Nutrient Reference Values into Practice: The German Dietary Scheme for the First Year of Life. Journal of Pediatric Gastroenterology and Nutri- 
tion, 71, 550-556. https://doi.org/10.1097/MPG.0000000000002846

[6] Hilbig, A., Lentze, M.J. and Kersting, M. (2012) Introduction and COMPOSITION of complementary Feeding. Scientific Evidence and Practical Guidelines in Germany. Monatsschrift Kinderheilkunde, 160, 1089-1095. (In German) https://doi.org/10.1007/s00112-012-2638-0

[7] Kersting, M., Clausen, C. and Alexy, U. (2012) Kinderernährungheute: Grundlagen und lebensmittelbezogene Ernährungsrichtlinien. Kinder- und Jugendarzt, 43, 433437.

[8] EFSA NDA Panel (EFSA Panel on Dietetic Products, Nutrition and Allergies) (2013) Scientific Opinion on Nutrient Requirements and Dietary Intakes of Infants and Young Children in the European Union. EFSA Journal, 11, 3408. https://doi.org/10.2903/j.efsa.2013.3408

[9] Bührer, C., Genzel-Boroviczény, O., Jochum, F., et al. (2014) Nutrition of Healthy Infants: Recommendations of the Nutrition Committee of the German Pediatric Society. Monatsschrift Kinderheilkunde, 162, 527-538.

[10] Koletzko, B., Bauer, C., Cierpka, M., et al. (2016) Nutrition and Physical Activity of Infants and Breastfeeding Women. Updated Recommendations by "Healthy StartYoung Family Network" an Initiative from INFORM. Monatsschrift Kinderheilkunde, 164, 771-798. https://doi.org/10.1007/s00112-016-0147-2

[11] American Academy of Pediatrics, Committee on Nutrition (2013) Pediatric Nutrition Handbook. 7th Edition, American Academy of Pediatrics (ed) Elk Grove Village.

[12] Fewtrell, M., Bronsky, J., Campoy, C., et al. (2017) Complementary Feeding: A Position Paper by the European Society for Paediatric Gastroenterology, Hepatology, and Nutrition (ESPGHAN) Committee on Nutrition. Journal of Pediatric Gastroenterology and Nutrition, 64, 119-132.

https://doi.org/10.1097/MPG.0000000000001454

[13] Gupta, R.S., Warren, C.M., Smith, B.M., et al. (2018) The Public Health Impact of Parent-Reported Childhood Food Allergies in the United States. Pediatrics, 142, e20181235. https://doi.org/10.1542/peds.2018-1235

[14] Perkin, M.R., Logan, K., Tseng, A., et al., EAT Study Team (2016) Randomized Trial of Introduction of Allergenic Foods in Breast-Fed Infants. New England Journal of Medicine, 374, 1733-1743. https://doi.org/10.1056/NEJMoa1514210

[15] Du Toit, G., Roberts, G., Sayre, P.H., et al., Learning Early about Peanut Allergy (LEAP) Study Team (2013) Identifying Infants at High Risk of Peanut Allergy: The Learning Early about Peanut Allergy (LEAP) Screening Study. Journal of Allergy and Clinical Immunology, 131, 135-143. https://doi.org/10.1016/j.jaci.2012.09.015

[16] Du Toit, G., Sayre, P.H., Roberts, G., et al., Immune Tolerance Network LEAP-On Study Team (2016) Effect of Avoidance on Peanut Allergy after Early Peanut Consumption. New England Journal of Medicine, 374, 1435-1443. https://doi.org/10.1056/NEJMoa1514209

[17] Lodge, C.J., Tan, D.J., Lau, M.X., et al. (2015) Breastfeeding and Asthma and Allergies: A Systematic Review and Meta-Analysis. Acta Paediatrica, 104, 38-53. https://doi.org/10.1111/apa.13132

[18] Heinrich, J. (2017) Modulation of Allergy Risk by Breast Feeding. Current Opinion in Clinical Nutrition and Metabolism Care, 20, 217-221. https://doi.org/10.1097/MCO.0000000000000366

[19] Boyle, R.J., Ierodiakonou, D., Khan, T., et al. (2016) Hydrolysed Formula and Risk of Allergic or Autoimmune Disease: Systematic Review and Meta-Analysis. British Medical Journal, 352, i974. https://doi.org/10.1136/bmj.i974 
[20] Kukkonen, K., Savilahti, E., Haahtela, T., et al. (2007) Probiotics and Prebiotic Galacto-Oligosaccharides in the Prevention of Allergic Diseases: A Randomized, DoubleBlind, Placebo-Controlled Trial. Journal of Allergy and Clinical Immunology, 119, 192-198. https://doi.org/10.1016/j.jaci.2006.09.009

[21] Baï, N., Just, J., Chastang, J., et al. (2019) Maternal Diet before and during Pregnancy and Risk of Asthma and Allergic Rhinitis in Children. Allergy, Asthma \& Clinical Immunology, 15, Article No. 40. https://doi.org/10.1186/s13223-019-0353-2

[22] Bunyavanich, S., Rifas-Shiman, S.., Platts-Mills, T.A., et al. (2014) Peanut, Milk, and Wheat Intake During Pregnancy Is Associated with Reduced Allergy and Asthma in Children. Journal of Allergy and Clinical Immunology, 133, 1373-1382.

https://doi.org/10.1016/j.jaci.2013.11.040

[23] Perkin, M.R., Logan, K., Marrs, T., et al. (2016) Enquiring about Tolerance (EAT) Study: Feasibility of an Early Allergenic Food Introduction Regimen. Journal of Allergy and Clinical Immunology, 137, 1477-1486.e8. https://doi.org/10.1016/j.jaci.2015.12.1322

[24] Øien, T., Schjelvaag, A., Storrø, O., Johnsen, R. and Simpson, M.R. (2019) Fish Consumption at One Year of Age Reduces the Risk of Eczema, Asthma and Wheeze at Six Years of Age. Nutrients, 11, 1969. https://doi.org/10.3390/nu11091969

[25] Du Toit, G., Katz, Y., Sasieni, P., et al. (2008) Early Consumption of Peanuts in Infancy Is Associated with a Low Prevalence of Peanut Allergy. Journal of Allergy and Clinical Immunology, 122, 984-991. https://doi.org/10.1016/j.jaci.2008.08.039

[26] Koplin, J.J., Osborne, N.J., Wake, M., et al. (2010) Can Early Introduction of Egg Prevent Egg Allergy in Infants? A Population-Based Study. Journal of Allergy and Clinical Immunology, 126, 807-813. https://doi.org/10.1016/j.jaci.2010.07.028

[27] Snijders, B.E., Thijs, C., van Ree, R. and van den Brandt, P.A. (2008) Age at First Introduction of Cow Milk Products and Other Food Products in Relation to Infant Atopic Manifestations in the First 2 Years of Life: The KOALA Birth Cohort Study. Pediatrics, 122, e115-e122. https://doi.org/10.1542/peds.2007-1651

[28] Mori, F., Barni, S., Liccioli, G. and Novembre, E. (2019) Oral Immunotherapy (OIT): A Personalized Medicine. Medicina (Kaunas), 55, 684. https://doi.org/10.3390/medicina55100684

[29] Mikkelsen, A., Galli, C., Eiben, G., et al. (2017) Blood Fatty Acid Composition in Relation to Allergy in Children Aged 2 - 9 Years: Results from the European IDEFICS Study. European Journal of Clinical Nutrition, 71, 39-44. https://doi.org/10.1038/ejcn.2016.158

[30] Sausenthaler, S., Koletzko, S., Schaaf, B., et al. (2007) Maternal Diet during Pregnancy in Relation to Eczema and Allergic Sensitization in the Offspring at $2 \mathrm{y}$ of Age. American Journal of Clinical Nutrition, 85, 530-537.

https://doi.org/10.1093/ajcn/85.2.530

[31] Rzehak, P., Thijs, C., Standl, M., et al. (2010) Variants of the FADS1 FADS2 Gene Cluster, Blood Levels of Polyunsaturated Fatty Acids and Eczema in Children within the First 2 Years of Life. PLoS ONE, 5, e13261. https://doi.org/10.1371/journal.pone.0013261

[32] Weisse, K., Winkler, S., Hirche, F., et al. (2013) Maternal and Newborn Vitamin D Status and Its Impact on Food Allergy Development in the German LINA Cohort Study. Allergy, 68, 220-228. https://doi.org/10.1111/all.12081

[33] Seyedrezazadeh, E., Moghaddam, M.P., Ansarin, K., et al. (2014) Fruit and Vegetable Intake and Risk of Wheezing and Asthma: A Systematic Review and Meta-Analysis. Nutrition Review, 72, 411-428. https://doi.org/10.1111/nure.12121 
[34] Alwarith, J., Kahleova, H., Crosby, L., et al. (2020) The Role of Nutrition in Asthma Prevention and Treatment. Nutrition Reviews, 78, 928-938. https://doi.org/10.1093/nutrit/nuaa005

[35] Corica, D., Aversa, T., Caminiti, L., Lombardo, F., Wasniewska, M. and Pajno, G.B. (2020) Nutrition and Avoidance Diets in Children with Food Allergy. Frontiers in Pediatrics, 8, 518. https://doi.org/10.3389/fped.2020.00518

[36] de Silva, D., Halken, S., Singh, C., et al. (2020) Preventing Food Allergy in Infancy and Childhood: Systematic Review of Randomised Controlled Trials. Pediatric Allergy and Immunology, 31, 813-826.

[37] Kagalwalla, A.F., Sentongo, T.A., Ritz, S., et al. (2006) Effect of Six-Food Elimination Diet on Clinical and Histologic Outcomes in Eosinophilic Esophagitis. Clinical Gastroenterology and Hepatology, 4, 1097-1102. https://doi.org/10.1016/j.cgh.2006.05.026

[38] Riva, E., Fiocchi, A., Agostoni, C., et al. (1994) PKU-Related Dysgammaglobulinaemia: The Effect of Diet Therapy on IgE and Allergic Sensitization. Journal of Inherited Metabolic Diseases, 17, 710-717. https://doi.org/10.1007/BF00712013

[39] Bouvard, V., Loomis, D., Guyton, K.Z., et al. (2015) Carcinogenicity of Consumption of Red and Processed Meat. The Lancet Oncology, 16, 1599-1600. https://doi.org/10.1016/S1470-2045(15)00444-1

[40] Boeing, H., Bechthold, A., Bub, A., et al. (2012) Critical Review: Vegetables and Fruit in the Prevention of Chronic Diseases. European Journal of Clinical Nutrition, 51, 637-663. https://doi.org/10.1007/s00394-012-0380-y

[41] German Society for Nutrition (DGE) (2011) Evidence-Based Guideline: Carbohydrate Intake and Prevention of Dietary-Related Diseases. Bonn. https://www.dge.de/wissenschaft/leitlinien/leitlinie-kohlenhydrate/

[42] Appleby, P.N. and Key, T.J. (2016) The Long-Term Health of Vegetarians and Vegans. Proceeding of the Nutrition Society, 75, 287-293. https://doi.org/10.1017/S0029665115004334

[43] Medawar, E., Huhn, S., Villringer, A., et al. (2019) The Effects of Plant-Based Diets on the Body and the Brain: A Systematic Review. Translational Psychiatry, 9, Article No. 226. https://doi.org/10.1038/s41398-019-0552-0

[44] Dinu, M., Abbate, R., Gensini, G.F., et al. (2017) Vegetarian, Vegan Diets and Multiple Health Outcomes: A Systematic Review with Meta-Analysis of Observational Studies. Critical Reviews in Food Science and Nutrition, 57, 3640-3649. https://doi.org/10.1080/10408398.2016.1138447

[45] Sabate, J. and Wien, M. (2010) Vegetarian Diets and Childhood Obesity Prevention. American Journal of Clinical Nutrition, 91, 1525S-1529S.

https://doi.org/10.3945/ajcn.2010.28701F

[46] Craddock, J.C., Neale, E.P., Peoples, G.E. and Probst, Y.C. (2019) Vegetarian-Based Dietary Patterns and Their Relation with Inflammatory and Immune Biomarkers: A Systematic Review and Meta-Analysis. Advances in Nutrition, 10, 433-451. https://doi.org/10.1093/advances/nmy103

[47] Kerschke-Risch, P. (2015) Vegan Diet: Motives, Approach and Duration. Initial Results of a Quantitative Sociological Study. Ernährungs Umschau, 62, 98-103.

[48] Appleby, P.N, , Crowe, F.L., Bradbury, K.E., et al. (2016) Mortality in Vegetarians and Comparable Non Vegetarians in the United Kingdom. American Journal of Clinical Nutrition, 103, 218-230. https://doi.org/10.3945/ajcn.115.119461

[49] Ströhle, A., Löser, C., Behrendt, I., et al. (2016) Alternative Diets Part 1: Overview and Vegetarian Diets. Aktuelle Ernährungsmedizin, 41, 47-65. (In German) 
https://doi.org/10.1055/s-0041-111459

[50] Judge, M., Boeing, H., Grünewald-Funk, D., et al. (2016) Vegan Nutrition. Position of the German Society for Nutrition (DGE). Nutrition Review, 63, 92-102.

[51] Prell, C. and Koletzko, B. (2014) Restrictive Diets. Risk of Malnutrition and Preventive Options. Monatsschrift Kinderheilkunde, 162, 503-510. (In German) https://doi.org/10.1007/s00112-013-3070-9

[52] German Society for Nutrition (DGE), Austrian Society for Nutrition (ÖGE), Swiss Society for Nutrition (SGE) (2016) D-A-CH. Reference Values for the Nutrient Supply. 2. Aufl, Umschau Verlag, Deutschland.

[53] Kersting, M., Alexy, U. and Schürmann, S. (2016) Critical Dietary Habits in Early Childhood: Principles and Practice. In: Biesalski, H.K. and Black, R.E., Eds., Hidden Hunger. Malnutrition and the First 1000 Days of Life: Causes, Consequences and Solutions, World Review of Nutrition and Dietetics, Vol. 115, Karger, Basel, 24-35. https://doi.org/10.1159/000441885

[54] Schürmann, S., Kersting, M. and Alexy, U. (2017) Vegetarian Diets in Children: A Systematic Review. European Journal of Nutrition, 56, 1797-1817.

https://doi.org/10.1007/s00394-017-1416-0

[55] Burkert, N.T., Muckenhuber, J., Großschädl, F., Rásky, E. and Freidl, W. (2014) Nutrition and Health-The Association between Eating Behavior and Various Health Parameters: A Matched Sample Study. PLoS ONE, 9, e88278. https://doi.org/10.1371/journal.pone.0088278

[56] Skypala, I.J. and McKenzie, R. (2019) Nutritional Issues in Food Allergy. Clinical Review of Allergy and Immunology, 57, 166-178.

https://doi.org/10.1007/s12016-018-8688-x

[57] Kersting, M. (2013) Alternative Nutrition. In: Rodeck, B. and Room, K.P., Eds., Pediatric Gastroenterology, Hepatology and Nutrition, Springer, Berlin, Heidelberg, Germany, 605-609. https://doi.org/10.1007/978-3-642-24710-1 27

[58] Craig, W.J. and Mangels, A.R. (2009) Position of the American Dietetic Association: Vegetarian Diets. Journal of the American Dietetic Association, 109, 1266-1282. https://doi.org/10.1016/j.jada.2009.05.027

[59] Amit, M. (2010) Vegetarian Diets in Children and Adolescents. Paediatrics \& Child Health, 15, 303-314.

[60] Kalhoff, H. and Kersting, M. (2017) Programming Long-Term Health: Nutrition and Diet in Infants Aged 6 Months to 1 Year. In: Saavedra, J.M. and Dattilo, A.M., Eds., Early Nutrition and Long-Term Health: Mechanisms, Consequences, and Opportunities, Elsevier, Oxford, England, 499-536. https://doi.org/10.1016/B978-0-08-100168-4.00019-7

[61] Protudjer, J.L.P. and Mikkelsen, A. (2020) Veganism and Paediatric Food Allergy: Two Increasingly Prevalent Dietary Issues That Are Challenging When Co-Occurring. BMC Pediatrics, 20, Article No. 341. https://doi.org/10.1186/s12887-020-02236-0

[62] Eussen, S., Alles, M., Uijterschout, L., et al. (2015) Iron Intake and Status of Children Aged 6 - 36 Months in Europe: A Systematic Review. Annals of Nutrition and Metabolism, 66, 80-92. https://doi.org/10.1159/000371357

[63] Libuda, L., Hilbig, A., Berber-Al-Tawil, S., et al. (2018) Association between Full Breastfeeding, Timing of Complementary Food Introduction, and Iron Status in Infancy in Germany: Results of a Secondary Analysis of a Randomized Trial. European Journal of Nutrition, 57, 523-531. https://doi.org/10.1007/s00394-016-1335-5

[64] Kalhoff, H. and Kersting, M. (2017) Breastfeeding or Formula Feeding and Iron Status in the Second 6 Months of Life: A Critical Role for Complementary Feeding. 
Journal of Pediatrics, 187, 333. https://doi.org/10.1016/j.jpeds.2017.03.005

[65] Gilsing, A.M., Crowe, F.L., Lloyd-Wright, Z., et al. (2010) Serum Concentrations of Vitamin B12 and Folate in British Male Omnivores, Vegetarians and Vegans: Results from a Cross-Sectional Analysis of the EPIC-Oxford Cohort Study. European Journal of Clinical Nutrition, 64, 933-939. https://doi.org/10.1038/ejcn.2010.142

[66] Wabitsch, M., Koletzko, B. and Moß, A. (2011) Vitamin D Supply in Infancy, Childhood and Adolescence. Monatsschrift Kinderheilkunde, 159, 766-774. (In German) https://doi.org/10.1007/s00112-011-2407-5

[67] Waldmann, A., Koschizke, J. W., Leitzmann, C., et al. (2003) Dietary Intakes and Lifestyle Factors of a Vegan Population in Germany: Results from the German Vegan Study. European Journal of Clinical Nutrition, 57, 947-955. https://doi.org/10.1038/sj.ejcn.1601629

[68] Ambroszkiewicz, J., Klemarczyk, W., Gajewska, J., et al. (2010) The Influence of Vegan Diet on Bone Mineral Density and Biochemical Bone Turnover Markers. Pediatric Endocrinology Diabetes and Metabolism, 16, 201-204.

[69] Gap, T., Korenke, G.C., Poggenburg, I., et al. (20079 Maternal Vitamin-B12 Deficiency: Cause for Neurological Symptoms in Infancy. Journal of Obstetrics and Neonatology, 211, 157-161.

[70] Lücke, T., Korenke, G.C., Poggenburg, I., et al. (2007) Maternal Vitamin B12 Deficiency: Cause for Neurological Symptoms in Infancy. Zeitschrift für Geburtshilfe und Neonatologie, 211, 157-161. (In German) https://doi.org/10.1055/s-2007-981249

[71] Lentze, M.J. (2010) Vegetarian Diet and Diets for Outsiders in Childhood. Monatsschrift Kinderheilkunde, 149, 19-24. (In German) https://doi.org/10.1007/s001120050718

[72] Bhatia, J., Greer, F. and Committee on Nutrition, American Academy of Pediatrics (2008) Use of Soy Protein-Based Formulas in Infant Feeding. Pediatrics, 121, 10621068. https://doi.org/10.1542/peds.2008-0564

[73] Adgent, M.A., Umbach, D.M., Zemel, B.S., et al. (2018) A Longitudinal Study of Estrogen-Responsive Tissues and Hormone Concentrations in Infants Fed Soy Formula. Journal of Clinical Endocrinology and Metabolism, 103, 1899-1909. https://doi.org/10.1210/jc.2017-02249

[74] van Spronsen, F.J., van Wegberg, A.M., Ahring, K., et al. (2017) Key European Guidelines for the Diagnosis and Management of Patients with Phenylketonuria. The Lancet Diabetes \& Endocrinology, 5, 743-756. https://doi.org/10.1016/S2213-8587(16)30320-5

[75] De Abreu, D., Guessous, I., Vaucher, J., et al. (2013) Low Compliance with Dietary Recommendations for Food Intake among Adults. Clinical Nutrition, 32, 783-788. https://doi.org/10.1016/j.clnu.2012.11.022

[76] Greer, F.R., Sicherer, S.H. and Burks, A.W., Committee on Nutrition, Section on Allergy and Immunology (2019) The Effects of Early Nutritional Interventions on the Development of Atopic Disease in Infants and Children: The Role of Maternal Dietary Restriction, Breastfeeding, Hydrolyzed Formulas, and Timing of Introduction of Allergenic Complementary Foods. Pediatrics, 143, e20190281. https://doi.org/10.1542/peds.2019-0281

[77] Comberiati, P., Costagliola, G., D’Elios, S. and Peroni, D. (2019) Prevention of Food Allergy: The Significance of Early Introduction. Medicina (Kaunas), 55, 323. https://doi.org/10.3390/medicina55070323 